January 2014

\title{
Applying consensus criteria to the evaluation of patients with suspected chronic lymphocytic leukemia/small lymphocytic lymphoma
}

E. Mulwa-Babu

Aga Khan University

Riyat Malkit

Aga Khan University, riyat.malkit@aku.edu

D. Parech

University of Nairobi

Follow this and additional works at: http://ecommons.aku.edu/eastafrica_fhs_mc_pathol

Part of the Pathology Commons

\section{Recommended Citation}

Mulwa-Babu, E., Malkit, R., Parech, D. (2014). Applying consensus criteria to the evaluation of patients with suspected chronic lymphocytic leukemia/small lymphocytic lymphoma. African Journal of Cancer, 6(4), 215-217.

Available at: http://ecommons.aku.edu/eastafrica_fhs_mc_pathol/127 


\title{
Applying Consensus Criteria to the Evaluation of Patients with Suspected Chronic Lymphocytic Leukemia/Small Lymphocytic Lymphoma
}

\section{Application des critères de consensus pour le diagnostic de la leucémie lymphoïde chronique}

\author{
E. Mulwa-Babu • D. Paresh • M. Riyat \\ Received: 27 March 2014; Accepted: 12 May 2014 \\ (C) Lavoisier SAS 2014
}

\begin{abstract}
We describe a series of 5 patients in whom the application of consensus criteria for the diagnosis of chronic lymphocytic leukemia (CLL) led to a revised diagnosis. These patients had been recruited in a wider study describing the occurrence of CLL in Kenya. This case series highlights some of the pitfalls of making a diagnosis of CLL without incorporating all criteria.
\end{abstract}

\section{Keywords Pitfalls $\cdot$ CLL $\cdot$ Diagnosis}

Résumé Nous décrivons une série de cinq patients chez lesquels l'application des critères de consensus pour le diagnostic de la leucémie lymphoïde chronique (LLC) a conduit à une révision du diagnostic. Ces patients ont été recrutés dans une étude plus large décrivant la LLC au Kenya. Cette série de cas met en lumière les pièges dans le diagnostic de la LLC quand tous les critères n'y sont pas intégrés.

Mots clés Pièges $\cdot$ LLC $\cdot$ Diagnostic

\section{Introduction}

The laboratory diagnosis of lymphoma has evolved over the years from being based on morphology alone to the inclusion of immunophenotyping and molecular data [1-3]. Specifically, the diagnosis of chronic lymphocytic leukemia (CLL) according to the World Health Organization (WHO)

E. Mulwa-Babu $(\bowtie) \cdot$ M. Riyat

Department of pathology, Aga Khan University Hospital,

Nairobi, Kenya

e-mail : evenduku@yahoo.co.uk

D. Paresh

University of Nairobi, Uhuru Highway, Nairobi 00100, Kenya and the International Workshop on CLL (IWCLL) requires the following $[3,4]$ :

- Duration: Persistent lymphocytosis $\geq 3$ months;

- Counts: Monoclonal B cell count $\geq 5 \times 10^{9} / \mathrm{L}$ when there is lymphocytosis only;

- Morphology: Consistent morphology as defined by the French-American-British (FAB) classification [5];

- Immunophenotype: The prototype is co-expression of CD5 and CD23 in monoclonal B cells with dim expression of surface immunoglobulin (sIg) and absent/dim CD79b (or CD22), and the absence of expression of FMC7. The scoring system described by Matutes et al. can help distinguish CLL from other non-Hodgkin lymphomas (NHL) on the basis of immunophenotype [6,7].

Small lymphocytic lymphoma (SLL) and CLL are different presentations of the same disease [4].

\section{Materials and methods}

Patients were recruited as part of a wider study describing the occurrence of CLL in Kenya [8]. Morphological evaluation was by FAB criteria. Results of immunophenotyping were interpreted based on the scoring system described by Matutes et al. [6,7].

\section{Results}

Criteria: Duration and counts

\section{Case 1: Case of essential thrombocythemia}

A 62-year-old man was referred to Aga Khan University Hospital, Nairobi (AKUH,N) for bone marrow evaluation with a new diagnosis of CLL. The basis for this diagnosis 
was uncertain as records were not accessible. However, history was significant for erythromelalgia and persistent thrombocytosis, and the patient had not received any therapy for CLL. Physical examination was noteworthy for the presence of moderate splenomegaly. Interestingly, the patient did not have lymphocytosis. Subsequent blood counts were also negative for lymphocytosis. There was no evidence of reactive thrombocytosis and bone marrow evaluation done was consistent with essential thrombocythemia (ET).

\section{Criterion: Morphology}

\section{Case 2: Case of HCL}

A 61-year-old man was seen at AKUH,N seeking a second medical opinion. He had been on follow-up as a case of CLL. Clinical history was remarkable for recurrent anemia, thrombocytopenia, and non-response to chlorambucil therapy. Physical examination was notable for pallor and massive splenomegaly. Morphology was, however, inconsistent with CLL as per the FAB criteria (Fig. 1). Immunophenotyping confirmed the suspected diagnosis of hairy cell leukemia (HCL). The immunophenotype was CD5-, CD23 borderline, bright sIg expression with lambda restriction, CD11c/ CD22 co-expression with bright CD22 expression, FMC7 positive, and CD103+.

\section{Criterion: Immunophenotype}

\section{Case 3-5: Cases of diagnostic uncertainty}

Case 3 was a 50 -year-old female patient who had initially been diagnosed as CLL on morphological evaluation of a bone marrow aspirate. However, on immunophenotyping of a peripheral blood sample with leukocytosis, most cells were weak CD45 positive and suspicious for blasts. The

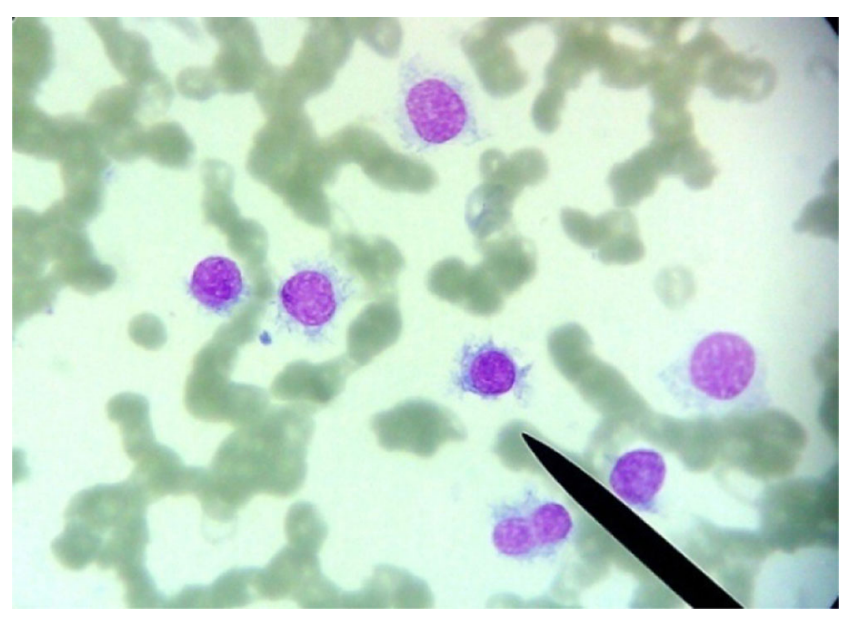

Fig. 1 Peripheral blood smear for Case 2 showing hairy cells cells were CD19 positive and lacked surface immunoglobulin expression. Further immunophenotyping confirmed the diagnosis of acute lymphoblastic leukemia (ALL) and an amended report was issued (Fig. 2).

Cases 4 and 5 were elderly male patients with sustained lymphocytosis. However, morphological evaluation was not conclusive due to the presence of cleaved cells and moderate amounts of cytoplasm (Fig. 3). A diagnosis of a chronic lymphoproliferative disorder (CLPD) was given and CLL/ SLL and follicular lymphoma were suggested as possibilities. The immunophenotype for both, however, scored 5/5 which is highly specific for CLL [6]. CD 10 was negative for both.

\section{Discussion}

The incorporation of relevant criteria for diagnosis of various hematological malignancies is not merely of academic

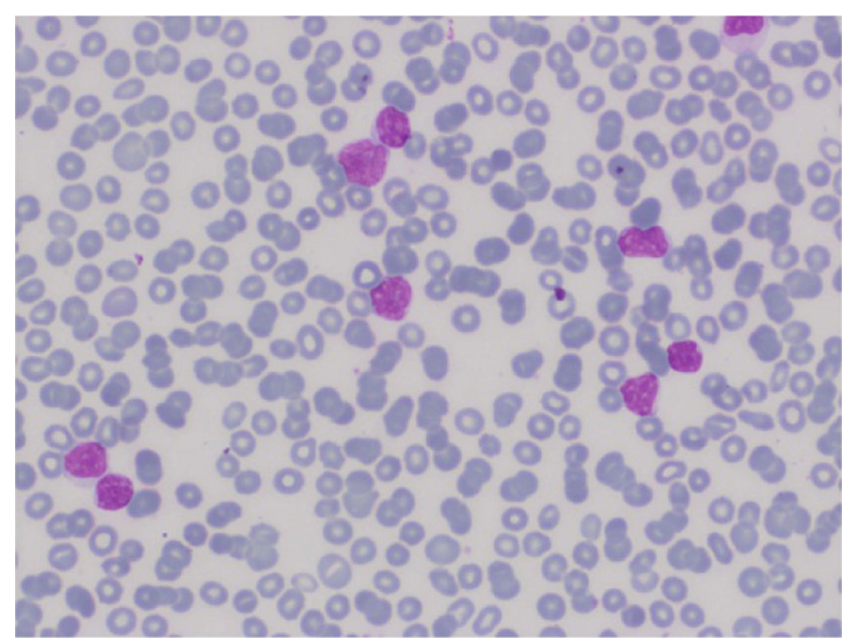

Fig. 2 Peripheral blood smear for Case 3

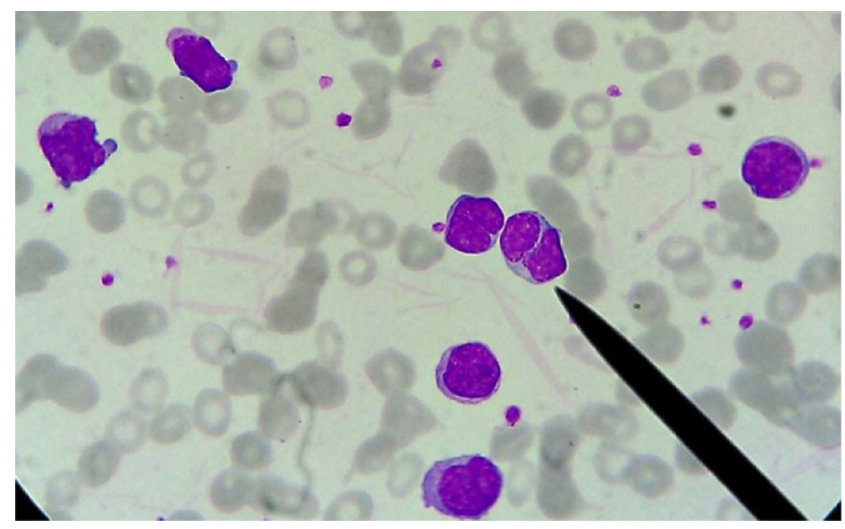

Fig. 3 Representative field of peripheral smear findings in Cases 4 and 5 
interest. It results in appropriate classification, prognostication, and management of patients. The management principles of ALL, HLL, and ET differ from those of CLL/SLL $[4,9]$. Altering the diagnosis for the patients described in this series, therefore, optimized their management.

While sub-Saharan Africa is plagued by resource limitations [10], incorporation of requisite criteria is vital when circumstances permit an optimal evaluation. However, even in the absence of access to more specialized tests like immunophenotyping, clinical correlation using simple criteria like the presence and persistence of lymphocytosis can go a long way in distinguishing transient from clonal causes of lymphocytosis. Building expertise in microscopy would also go a long way in the recognition of classic features such as those seen in Case 2.

\section{Conclusion}

The application of the WHO criteria for the diagnosis of lymphomas including CLL/SLL results in better definition of disease entities. Where resources allow, morphological evaluation should be supported by the relevant diagnostic tests.

Acknowledgments Dr. Etabale Mbayah for his assistance with translating the abstract into French.

Conflict of interest: E. Mulwa-Babu, D. Paresh, and M. Riyat have no conflicts of interest to declare.

Ethical standards: Approval for the study was obtained from the institution's research and ethics committees; con- sent was obtained from the patients; results were conveyed to attending physicians.

\section{References}

1. Gall EA, Mallory TB (1942) Malignant lymphoma: A clinicopathologic survey of 618 cases. Am J Pathol 18:381-429

2. Hicks EB, Rappaport H, Winter WJ (1956) Follicular lymphoma; a re-evaluation of its position in the scheme of malignant lymphoma, based on a survey of 253 cases. Cancer 9:792-821

3. Swerdlow SH, Campo E, Harris NL, et al (2008) WHO classification of tumours of haematopoietic and lymphoid tissues, 4th ed. IARC, Lyon, pp 180-2

4. Hallek M, Cheson BD, Catovsky D, et al (2008) Guidelines for the diagnosis and treatment of chronic lymphocytic leukemia: a report from the International Workshop on Chronic Lymphocytic Leukemia updating the National Cancer Institute-Working Group 1996 guidelines. Blood 111:5446-56

5. Bennett JM, Catovsky D, Daniel MT, et al (1989) Proposals for the classification of chronic (mature) B and T lymphoid leukaemias. French-American-British (FAB) Cooperative Group. J Clin Pathol 42:567-84

6. Matutes E, Owusu-Ankomah K, Morilla R, et al (1994) The immunological profile of B-cell disorders and proposal of a scoring system for the diagnosis of CLL. Leukemia 8:1640-5

7. Moreau EJ, Matutes E, A'Hern RP, et al (1997) Improvement of the chronic lymphocytic leukemia scoring system with the monoclonal antibody SN8 (CD79b). Am J Clin Pathol 108:378-82

8. Mulwa-Babu E, Paresh D, Riyat M (2013) Chronic lymphocytic leukemia in Kenya: an immunophenotypic and clinicopathologic study. Afr J Cancer 5:192-7

9. Beer P, Erber WN, Campbell PJ, Green AR (2011) How I treat essential thrombocythemia. Blood 117:1472-82

10. Naresh KN, Raphael M, Ayers L, et al (2011) Lymphomas in sub-Saharan Africa - what can we learn and how can we help in improving diagnosis, managing patients and fostering translational research? Br J Haematol 154:696-703 